\title{
ORÇAMENTO COMO INSTRUMENTO DE CONTROLE INTERNO PARA GESTÃO DAS INSTITUIÇÕES ECLESIÁSTICAS
}

\section{PRESUPUESTO COMO INSTRUMENTO DE CONTROL INTERNO PARA LA GESTIÓN DE LAS INSTITUCIONES ECLESIÁSTICAS}

\author{
Recebimento: 07/03/2018- Aceite: 13/10/2018- Publicação: 28/10/2018 \\ Processo de Avaliação: Double Blind Review
}

\author{
Aidê de Jesus Silva ${ }^{1}$ \\ Mestranda em Ciências Contábeis e Financeiras \\ Pontifícia Universidade Católica de São Paulo \\ aide.jesus@hotmail.com \\ Napoleão Verardi Galegale \\ Professor do Mestrado em Ciências Contábeis e Atuariais da Pontifícia Universidade \\ Católica de São Paulo \\ Professor Pesquisador do Centro Paula Souza \\ nvg@galegale.com.br \\ José Carlos Marion \\ Professor do Mestrado em Ciências Contábeis e Atuariais da Pontifícia Universidade \\ Católica de São Paulo \\ jcmarion@usp.br
}

\section{RESUMO}

Reconhecidas como entidades do terceiro setor, as Igrejas se veem atualmente diante de enormes desafios, toda estrutura sobrevive por meio de doações, o que potencializa a necessidade de uma gestão eficiente. Com o intuito de corroborar com os controles internos destas Instituições Eclesiásticas e ampliar a discussão acerca de estudos sobre gestão e contabilidade eclesiástica, esta pesquisa teve como objetivo verificar se o orçamento é utilizado como instrumento de controle interno para gestão das Dioceses e Arquidioceses presentes no Brasil. Para a pesquisa, utilizou-se o método de coletas de dados survey que possibilitou a interpretação dos dados obtidos por meio da análise de clusters, desenvolvidos com o software estatístico IBM SPSS Statistics, utilizando o método Two Step Cluster. Além disso, foi verificado na pesquisa o nível de maturidade do processo orçamentário elaborado nestas Instituições. Os resultados da pesquisa demonstram que estas Instituições utilizam o orçamento como instrumento de controle interno, no entanto, é importante que haja padronização do processo orçamentário para atender a todas as Dioceses e Arquidioceses. E o nível de maturidade em que se encontram estas Instituições é o nível três do processo

\footnotetext{
${ }^{1}$ Autor para correspondência: Pontifícia Universidade Católica de São Paulo - PUCSP- R.: Monte Alegre, 984- Perdizes- São Paulo- SP- Brasil CEP05014-90.
} 
orçamentário que compreende um processo definido; no entanto, com procedimentos não sofisticados, porém com formalização das práticas existentes.

Palavras-Chave: Gestão Eclesiástica. Controles internos. Orçamento.

\begin{abstract}
Recognized as nonprofit entities, the Churches currently see in front of enormous challenges, all structure survives through donations, which enhances the need for efficient management. In order to corroborate the internal controls of these ecclesiastical institutions and broaden the discussion of management studies and church accounting, this study aimed to verify if the budget is used as an internal control tool for management of Dioceses and Archdioceses present in Brazil. For the research we used the method of survey data collection that allowed the interpretation of data obtained through cluster analysis, developed with IBM SPSS Statistics statistical software using the Two Step Cluster method. In addition, it was found in the survey the level of maturity of the budget process developed in these institutions. The survey results show that these institutions use the budget as an internal control instrument, however, it is important that standardization of the budget process to meet all the Dioceses and Archdioceses. And the level of maturity where are these institutions is the third level budget process comprising a defined process; however, with no sophisticated procedures, but with formalization of existing practices.
\end{abstract}

Keywords: Ecclesiastical management. Internal controls. Budget.

\title{
RESUMEN
}

Reconocidas como entidades del tercer sector, las Iglesias se ven actualmente frente a enormes desafíos, toda estructura sobrevive por medio de donaciones, lo que potencia la necesidad de una gestión eficiente. Con el fin de corroborar con los controles internos de estas Instituciones Eclesiásticas y ampliar la discusión acerca de estudios sobre gestión y contabilidad eclesiástica, esta investigación tuvo como objetivo verificar si el presupuesto es utilizado como instrumento de control interno para gestión de las Diócesis y Arquidiocesis presentes en Brasil . Para la investigación se utilizó el método de recolección de datos survey que posibilitó la interpretación de los datos obtenidos por medio del análisis de clusters, desarrollados con el software estadístico IBM SPSS Statistics, utilizando el método Two Step Cluster. Además, se verificó en la investigación el nivel de madurez del proceso presupuestario elaborado en estas Instituciones. Los resultados de la investigación demuestran que estas instituciones utilizan el presupuesto como instrumento de control interno, sin embargo, es importante que haya estandarización del proceso presupuestario para atender a todas las diócesis y archidioceses. Y el nivel de madurez en que se encuentran estas Instituciones es el nivel tres del proceso presupuestario que comprende un proceso definido; sin embargo, con procedimientos no sofisticados, pero con formalización de las prácticas existentes. 
Palabras Clave: Gestión Eclesiástica. Controles internos. Presupuesto.

\section{INTRODUÇÃ̃O}

A Igreja Católica Apostólica Romana pode ser considerada a organização social mais influente e eficiente ao longo dos últimos séculos. Possui uma estrutura hierárquica complexa e organizada, o que a coloca diante de um alto grau de responsabilidade e transparência em suas ações.

Desta forma, reconhecidas como entidades do terceiro setor, as Igrejas se veem atualmente diante de enormes desafios dentro os quais podemos citar: organização do culto divino, sustento do clero, sustento dos seminários e seus formandos, mantenedores de obras sociais e de caridades, por meio de pastorais, e estrutura organizacional ampla e na maioria das vezes segregada. Ainda, toda estrutura sobrevive de doações, o que potencializa a necessidade de uma gestão eficiente.

Neste contexto, o orçamento nasce da necessidade do homem de antever eventos que possam comprometer a maximização de seus bens. "Assim, o orçamento pode ser definido como um plano dos processos operacionais para um determinado período. Ele é uma forma representativa dos objetivos econômico-financeiros a serem atingidos pela organização". (LUNKES, 2008, p.28).

O orçamento pode ser desenvolvido de várias formas, dependendo do tipo de organização e dos objetivos da organização em questão. As responsabilidades também devem estar bem definidas dentro da estrutura organizacional.

Para manter toda a estrutura organizacional presente em todo o mundo, com a complexidade e a abrangência das entidades que a compõem, a Igreja Católica Apostólica Romana tem como regimento interno o Código de Direito Canônico que é um conjunto de normas que disciplinam toda a vida eclesial.

O orçamento, para tanto, é um exigência disposta no código de direito canônico (Cân. 493 Cân. $494 \S 3$ e $\$ 4$ e Cân. 1284 §3), porém, como a estrutura administrativa hierárquica da Igreja apresenta-se de forma descentralizada, ou seja, o Vaticano, na figura do Papa, representa o que seria a Matriz e as Dioceses espalhadas pelo mundo, na figura dos Bispos, representam o que seriam as filiais e, cada Bispo é responsável por administrar sua filial, então, não é possível afirmar se há, nas Dioceses, uma cultura orçamentária e se estas se utilizam desse instrumento de controle interno para gestão.

Além disso, o orçamento tem ganhado um papel importante no âmbito das entidades do chamado terceiro setor, principalmente após a NBC TSP 1 (Normas Brasileiras de Contabilidade Aplicadas ao Setor Público) que destaca: "Informação suplementar, incluindo demonstrações não contábeis, pode ser apresentada junto com as demonstrações contábeis no intuito de proporcionar uma visão mais abrangente das atividades da entidade durante o período".

Desta forma, a presente pesquisa visa contribuir com a gestão da Igreja Católica Apostólica Romana e de outras Organizações Religiosas, através do estudo do orçamento 
como propulsor no processo de planejamento e controle das ações, auxiliando na tomada de decisão para destinação e aplicação dos recursos.

Diante do exposto, o estudo pretende responder a seguinte questão problema: "O orçamento é utilizado como instrumento de controle interno para gestão das Dioceses e Arquidioceses presentes no Brasil?".

O objetivo geral da pesquisa é estudar o orçamento como um instrumento de controle interno nas Instituições Eclesiásticas, contribuindo com a gestão dessas Instituições.

Delaméa (2001) aborda em seu livro sobre contabilidade eclesiástica alguns mecanismos de controle interno, entre eles o orçamento, no entanto a autora se atém às normas descritas no código do direito canônico.

A pesquisa realizada por West e Zech (2008) enfatiza a importância dos controles internos nas instituições do terceiro setor mais especificamente na Igreja Católica Apostólica Romana dos EUA, aborda de forma sucinta o orçamento como um dos mecanismos de controle interno, porém, o foco do trabalho é evidenciar a auditoria como forma de prevenção de fraudes e desvios.

Oliveira e Romão (2011) descrevem em uma abordagem voltada a entidades religiosas especificamente no contexto das paróquias como preparar um orçamento em três etapas. É uma abordagem simples e que não reflete o contexto amplo das Dioceses e Arquidioceses.

Diante das abordagens referenciadas acima e pesquisas efetuadas, não foram encontrados estudos que avaliassem os níveis de maturidade orçamentária destas Instituições. Portanto, torna-se importante destacar a contribuição acadêmica que esta pesquisa possibilitará, visto que existem poucos estudos acadêmicos que cercam essa temática.

\section{REFERENCIAL TEÓRICO}

\subsection{TERCEIRO SETOR}

Este termo Terceiro Setor vem do inglês Third Sector e foi inicialmente utilizada nos Estados Unidos na década de 1970 e posteriormente difundida pela Europa. No Brasil o termo passou a ser mais difundido após a década de 1990.

Conforme Hudson (2004, p. XI) :

O termo "terceiro setor" diferencia essas organizações do "setor privado" e do "setor público". O traço comum que une todas essas organizações é que são orientadas por valores: são criadas e mantidas por pessoas que acreditam que mudanças são necessárias e que desejam, elas mesmas, tomar providências nesse sentido.

Drucker (2002, p.XIV) coloca que "A instituição "sem fins lucrativos" não fornece bens ou serviços, nem controla. [...] Seu produto é um ser humano mudado. As instituições sem fins lucrativos são agentes de mudança humana".

Para Olak e Nascimento (2006, p.7) "[...] as entidades sem fins lucrativos existem para provocar mudanças nos indivíduos e, consequentemente, na sociedade. Entretanto, cada entidade deve definir, formal ou informalmente, sua própria filosofia". 
O Terceiro Setor corresponde a entidades privadas, sem fins lucrativos, com caráter social e que atuam nas áreas de interesse público. Neste sentido, pode-se dizer que o Terceiro Setor não é público e não pode ser considerada uma empresa privada com finalidade de lucro, porém é uma junção de ambos os setores.

Paes (2013, p.87) conceitua:

Podemos, assim, conceituar o Terceiro setor como o conjunto de organismos, organizações ou instituições sem fins lucrativos dotados de autonomia e administração própria que apresentam como função e objetivo principal atuar voluntariamente junto à sociedade civil visando ao seu aperfeiçoamento.

Desta forma, é importante esclarecer como se da à classificação organizacional destes setores segundo suas características, onde: o Primeiro Setor equivale às instituições governamentais, ou seja, ao Estado; o Segundo Setor compreende as empresas privadas com fins lucrativos; e, finalmente o Terceiro Setor com as entidades sem fins lucrativos.

Como o Estado muitas vezes deixar de cumprir com seu dever social, o terceiro setor surge como um elo entre o Estado e a sociedade, com a finalidade de promover ações e benefícios de caráter social.

Para Slomski et al. (2012, p.05) "[...] o terceiro setor pode ser entendido como uma conjunção do primeiro com o segundo setor, pois as entidades que compõem o terceiro setor possuem características tanto do Estado quanto do mercado".

Dentre as entidades do Terceiro Setor podemos destacar as ONGs (Organizações Não Governamentais), as Associações, as Fundações Privadas, os Partidos Políticos, as Organizações Religiosas, etc.

Paes (2013, p.97) coloca que "não existe, ainda, no âmbito do sistema normativo brasileiro, uma definição jurídica do que será esse Terceiro Setor, ou uma qualificação de entidades jurídicas já existentes para tarefas concernentes àquele"., porém, podemos buscar no Código Civil Brasileiro - Lei 10.406/2002 em seu art.44 as pessoas jurídicas de direito privado com interesse social, que são:

I - as associações;

II - as sociedades;

III - as fundações;

IV - as organizações religiosas;

V- os partidos políticos;

É importante destaca que recentemente foi aprovada a Lei $\mathrm{N}^{\mathrm{o}} 13.019$, de 31 Julho de 2014,que trata do regime jurídico das parcerias voluntárias do Terceiro Setor. Define diretriz para a política de fomento e de colaboração com organizações da sociedade civil, institui o termo de colaboração e o termo de fomento.

Considerada o Marco Regulatório das Organizações da Sociedade Civil, em termos gerais, esta lei fortalece a aplicação de controles internos e externos e a transparência na prestação de contas destas entidades que receberem transferências de recursos para a execução de projetos de interesse público. Esta Lei define em seu art. $2^{\circ} \S$ I organização da sociedade civil: 
Pessoa jurídica de direito privado sem fins lucrativos que não distribui, entre os seus sócios ou associados, conselheiros, diretores, empregados ou doadores, eventuais resultados, sobras, excedentes operacionais, brutos ou líquidos, dividendos, bonificações, participações ou parcelas do seu patrimônio, auferidos mediante o exercício de suas atividades, e que os aplica integralmente na consecução do respectivo objeto social, de forma imediata ou por meio da constituição de fundo patrimonial ou fundo de reserva.

Ainda, a Seção III da Lei trata da transparência e do controle que ambas as partes deverão divulgar a fim de que haja total transparência na aplicação dos recursos públicos.

\subsection{O TERCEIRO SETOR E A IGREJA CATÓLICA APOSTÓLICA ROMANA}

A prática assistencialista dos ricos, como forma da caridade Cristã, sustentou durante muito tempo hospitais, santas casas, asilos, educandários, entre outras organizações administradas pela Igreja. Assim, no Brasil, pode-se dizer que a Igreja Católica Apostólica Romana deu inicio as atividades sociais atuando nas mais diversas áreas de serviços à população.

Historicamente, a Igreja Católica Apostólica Romana esteve presente nos diversos setores da sociedade atuando em diversas áreas, como por exemplo: educação, saúde e assistência social. De certa forma, podemos dizer que ela cumpria um papel de Estado.

Segundo Slomski et al. (2012, p.05 apud FALCONER, 1999, p.95) "diversos autores consideram as Santas Casas de Misericórdia como as primeiras entidades do terceiro setor fundadas no Brasil, como, por exemplo, a Santa Casa de Santos, em 1543”.

Ainda, conforme Paes (2013, p.94):

Nos últimas décadas, com as grandes mudanças que aconteceram no mundo, a Igreja
Católica também mudou e, principalmente no Brasil, passou a dar prioridade à
remoção das causas que geravam milhões de pessoas necessitadas de esmolas.
Passou a denunciar as injustiças sociais, o "pecado estrutural" presente nas formas
de organização da sociedade.

Foi neste contexto que entre os anos de 1960 e 1970 surgiram, em meio à ditadura militar, as CEBs (Comunidades Eclesiais de Base) ligadas à Igreja Católica Apostólica Romana advogaram em favor dos menos favorecidos e que muitas, após atingirem um nível de organização, deram origem ao que hoje chamamos de ONGs.

\subsection{ORÇAMENTO COMO INSTRUMENTO DOS CONTROLES INTERNOS}

$\mathrm{O}$ orçamento nasce da necessidade do homem de antever eventos que possam comprometer a maximização de seus bens. Assim, o orçamento pode ser definido como um plano dos processos operacionais para um determinado período. Segundo Horngren, Sundem e Stratton, (2004, p.230) "o orçamento é uma ferramenta que apoia os gestores em suas funções de planejamento e controle. Um orçamento é um plano de negócios formal”. 
Para Oliveira, Perez Jr.. e Silva (2008, p.119) “o orçamento é um instrumento que traz a definição quantitativa dos objetivos e o detalhamento dos fatores necessários para atingi-los, assim como o controle do desempenho". Conforme Oliveira (2009, p.291) "a palavra orçamento é utilizada para descrever o plano geral de operações, expresso em termos quantitativos. Um orçamento de uma empresa consiste em um plano abrangendo todas as fases das operações para um período futuro definido".

Padoveze (2011, p.239) conceitua: “orçar significa processar todos os dados constantes do sistema de informação contábil de hoje, introduzindo os dados previstos para o próximo exercício, considerando as alterações já definidas para o próximo exercício".

Portanto, o orçamento pode ser considerando uma importante ferramenta de controle e gestão, uma vez que sua elaboração exige um estudo prévio e um acompanhamento contínuo dos resultados. "Os orçamentos, certamente, lidam com o que os gestores planejam para o futuro". (HORNGREN, SUNDEM E STRATTON, 2004, p.230).

"A simples preparação de um orçamento pode vir a ser considerável valor para uma empresa, no entanto seu maior valor reside nos aspectos de planejamento e na sua utilização para fins de coordenação e controle durante o período [...]”. (OLIVEIRA, 2009, p.290).

Horngren, Sundem e Stratton (2004, p.230) atribuem três benefícios do orçamento:

1. Os orçamentos compelem os gestores a pensar no futuro pela formalização de suas responsabilidades para planejar.

2. Os orçamentos fornecem expectativas definidas, que são a melhor estrutura para julgar o desempenho subsequente.

3. Os orçamentos ajudam os gestores na coordenação de seus esforços, de modo que os planos das subunidades da organização satisfaçam os objetivos da organização como um todo.

Verifica-se que a elaboração de um orçamento prepara os gestores de uma organização para lidar com possíveis mudanças ao longo do processo. Além disso, as metas tornam-se conhecidas por todos da organização facilitando o alcance dos objetivos traçados.

Segundo Delaméa (2001, p.159) "o orçamento, além de ser eficaz instrumento de coordenação da aplicação dos recursos financeiros, permite o controle entre o programa e a ação, e a relação entre o seu custo e o seu benefício [...]”.

Demonstrações contábeis orçamentárias não são obrigatórias para o segundo e terceiro setor, porém, NBC TSP 1 incentiva as entidades a apresentarem informações adicionais para auxiliar os usuários na avaliação do desempenho da entidade e na sua administração dos recursos (ativos), assim como auxiliar aos usuários a tomar decisões e avaliar sobre a alocação de recursos; e a NBC TSP 24 cuja norma se aplica às entidades do setor público que tem a obrigatoriedade de apresentar informação orçamentária nas demonstrações.

Ainda, Delaméa (2001) enfatiza que por meio dos orçamentos, fixam-se limites gerenciais e se estabelecem parâmetros para investimentos, ou seja, metas claras e definidas, e isso implica produzir orçamentos que não sejam fruto do imaginário; portanto deve haver responsabilidade em sua confecção, porque se trata de peça técnica especializada, um importante instrumento de controle que necessita de alicerces sólidos como os fornecidos pela contabilidade.

Segundo Lunkes (2008, p.31): 
Uma vez que o orçamento foi adotado, deve ser uma ferramenta importante para avaliar o desempenho. As variações entre o resultado atual e o estimado devem ser sistemática e periodicamente revisadas para determinar sua causa. Assim, os colaboradores não devem ser responsabilizados por variações que estão além do controle. As condições de implementação vão depender em grande parte do tipo de empresa e principalmente do grau de utilização do próprio processo orçamentário.

\subsection{ORÇAMENTO COMO PROCESSO E O MODELO DE MATURIDADE GENÉRICO}

É importante colocar que a cultura organizacional é fator de grande importância no processo orçamentário. Para Tarifa, Almeida e Espejo (2009, p.1) "As estruturas de crenças, valores e costumes nas organizações formam o alicerce e influenciam de modo direto ou indireto as práticas operacionais e administrativas cotidianas". Assim, o processo orçamentário quando bem definido e estruturado se torna uma importante ferramenta de gestão.

Organizar através de processos é, segundo Gonçalves (2000, p.11), "projetar e mensurar cuidadosamente seus processos e fazer com que todos os funcionários entendam e se responsabilizem por eles, possibilitando o desenvolvimento de um sentimento de propriedade do processo".

Tarifa, Almeida e Espejo (2009, p.2) colocam que:

Após a definição das diretrizes de projeções futuras que devem ser obtidas por um processo de profunda e ampla análise de cenário, o orçamento empresarial é o instrumento de gestão mais relevante do processo de planejamento operacional. Nele são sintetizadas informações que irão orientar as atividades de todos os gestores dos diversos níveis hierárquicos, nos períodos de abrangência dos orçamentos elaborados.

Gonçalves (2000, p.13) esclarece que "modernas ferramentas de gestão empresarial, como os sistemas informatizados integrados do tipo ERP (Enterprise Resource Planning) pressupõem que a gestão da empresa se dê por processos".

Gonçalves (2000, p.13) coloca ainda que:

A empresa estruturada por processos não é necessariamente gerida por processos e
vice-versa. Muitas vezes, a gestão das empresas ocorre de acordo com as ideias e os
procedimentos antigos, típicos das organizações funcionais, mesmo quando elas
estão querendo se organizar por processos. Outras vezes, as pessoas tentam
administrar suas empresas por processos (inclusive com o emprego de sistemas
informatizados especificamente projetados para isso) sem, no entanto, estruturá-las
da maneira adequada.

Coordenar as atividades é essencial para o sucesso de qualquer procedimento a ser implantando com o intuito de otimizar resultados e, com todas as variáveis que podem 
influenciar na implantação do processo orçamentário, o modelo de maturidade genérico ajuda a compreender em que estágio de maturidade encontra-se o processo orçamentário em determinada organização e quais passos deverão ser realizados para seu progresso.

Atualmente existem vários modelos de maturidade, nesta pesquisa estudaremos e aplicaremos o modelo de maturidade sugerido pelo IT Governance Institute (ITGI). O ITGI foi criado em 1998 com o intuito de melhorar os padrões internacionais de direção e controle da tecnologia da informação nas organizações, ou seja, uma governança de TI. Para isso, foi elaborado um manual $o$ Control Objectives for Information and related Technology (COBIT).

$\mathrm{O}$ modelo de maturidade sugerido pelo COBIT 4.1 além de permitir uma adaptação para diversas situações no qual é necessário saber o estágio atual da empresa, permite uma avaliação da situação à qual se encontra a organização e a identificação dos processos a serem implementados para atingir novas metas.

Este modelo, conforme descrito no COBIT 4.1 (2007, p.19), permite:

1. Uma medida relativa de onde a empresa está;

2. Uma maneira de eficientemente decidir para onde ir;

3. Uma ferramenta para avaliação do progresso em relação às metas.

Ainda, segundo COBIT 4.1 (2007, p.22):

Os modelos de maturidade são construídos a partir do modelo qualitativo genérico no qual os princípios dos seguintes atributos são adicionados de maneira crescente através dos níveis:

- Consciência e comunicação;

- Políticas, planos e procedimentos;

- Ferramentas e automação;

- Habilidades e especialização;

- Responsabilidade e responsabilização;

- Definição de objetivos e medição. 


\section{Figura 1 - Modelo de Maturidade Genérico}

0 Inexistente - Completa falta de um processo reconhecido. A empresa nem mesmo reconheceu que existe uma questão a ser trabalhada.

1 Inicial / Ad hoc - Existem evidências que a empresa reconheceu que existem questões e que precisam ser trabalhadas. No entanto, não existe processo padronizado; ao contrário, existem enfoques Ad Hoc que tendem a ser aplicados individualmente ou caso-a-caso. 0 enfoque geral de gerenciamento é desorganizado.

2 Repetivel, porém Intuitivo - Os processos evoluiram para um estágio onde procedimentos similares são seguidos por diferentes pessoas fazendo a mesma tarefa. Não existe um treinamento formal ou uma comunicação dos procedimentos padronizados e a responsabilidade é deixado com o indivíduo. Há um alto grau de confiança no conhecimento dos individuos e consequentemente erros podem ocorrer.

3 Processo Definido - Procedimentos foram padronizados, documentados e comunicados através de treinamento. É mandatório que esses processos sejam seguidos; no entanto, possivelmente desvios não serão detectados. Os procedimentos não são sofisticados mas existe a formalização das práticas existentes.

4 Gerenciado e Mensurável - A gerencia monitora e mede a aderência aos procedimentos e adota ações onde os processos parecem não estar funcionando muito bem. Os processos estão debaixo de um constante aprimoramento e fornecem boas práticas. Automação e ferramentas são utilizadas de uma maneira limitada ou fragmentada.

5 Otimizado - Os processos foram refinados a um nivel de boas práticas, baseado no resultado de um contínuo aprimoramento e modelagem da maturidade como outras organizações. TI é utilizada como um caminho integrado para automatizar o fluxo de trabalho, provendo ferramentas para aprimorar a qualidade e efetividade, tornando a organização rápida em adaptar-se.

Fonte: IT Governance Institute-www.itgi.org. (2007, p.21).

Verifica-se por meio do modelo de maturidade que as organizações podem identificar em que estágio estão e quais os passos a serem tomados para que possam atingir novas metas e aumentar o seu potencial, adquirindo novas habilidades e aperfeiçoando técnicas já utilizadas. Avaliações constantes deverão fazer parte da aplicação do modelo de maturidade a fim de promover melhorias.

É importante que os gestores dessas organizações tenham conhecimento sobre modelos de estágios de maturidade e os indicadores de cada nível de maturidade a fim de obter um melhor resultado na implantação de processos que podem ter um custo elevado, como também para obter melhores resultados nas metas definidas pela organização.

Baseando-se no modelo de maturidade genérico do COBIT iremos elaborar um Modelo de Maturidade para o Processo Orçamentário.

Quadro 1 - Modelo de Maturidade para Processo Orçamentário

\begin{tabular}{|c|c|c|}
\hline $\begin{array}{c}\text { Nível de } \\
\text { Maturidade }\end{array}$ & Estágio do Processo Orçamentário & $\begin{array}{l}\text { Estabelecimento do Processo } \\
\text { Orçamentário }\end{array}$ \\
\hline O Inexistente & $\begin{array}{l}\text { Não existe o reconhecimento da } \\
\text { necessidade de um processo } \\
\text { orçamentário. Processos orçamentários } \\
\text { não são parte da cultura ou missão da } \\
\text { organização. }\end{array}$ & $\begin{array}{l}\text { Não existe a intenção de implantar um } \\
\text { processo orçamentário. }\end{array}$ \\
\hline 1 Inicial / Ad hoc & $\begin{array}{l}\text { A organização começa a reconhecer que } \\
\text { um processo orçamentário é necessário. } \\
\text { No entanto, não existe processo } \\
\text { padronizado. }\end{array}$ & $\begin{array}{l}\text { Existem enfoques Ad Hoc que tendem a } \\
\text { ser aplicados individualmente ou caso a } \\
\text { caso. O enfoque geral de gerenciamento é } \\
\text { desorganizado. }\end{array}$ \\
\hline
\end{tabular}




\begin{tabular}{|c|c|c|}
\hline $\begin{array}{l}2 \text { Repetível, porém } \\
\text { Intuitivo }\end{array}$ & $\begin{array}{l}\text { Orçamentos estão em execução, mas não } \\
\text { são documentados. A sua operação é } \\
\text { dependente do conhecimento e da } \\
\text { motivação das pessoas. Neste estágio os } \\
\text { funcionários podem não estar } \\
\text { conscientes de suas responsabilidades. }\end{array}$ & $\begin{array}{l}\text { Avaliações da necessidade do orçamento } \\
\text { ocorrem quando necessário. Uma reunião } \\
\text { com enfoque informal é realizada para } \\
\text { definir algumas questões. }\end{array}$ \\
\hline 3 Processo Definido & $\begin{array}{l}\text { O Processo orçamentário está } \\
\text { documentado. É mandatório que esses } \\
\text { processos sejam seguidos; no entanto, } \\
\text { possivelmente alguns problemas não } \\
\text { serão detectados. Os procedimentos não } \\
\text { são sofisticados, mas existe a } \\
\text { formalização das práticas existentes. }\end{array}$ & $\begin{array}{l}\text { A execução do processo orçamentário } \\
\text { passa a ser realizada por equipes ou áreas. } \\
\text { As estruturas organizacionais já estão } \\
\text { constituídas. }\end{array}$ \\
\hline $\begin{array}{l}4 \text { Gerenciado e } \\
\text { Mensurável }\end{array}$ & $\begin{array}{l}\text { Gerencia, monitora, avalia e adota ações } \\
\text { para a melhor condução do processo } \\
\text { orçamentário. Os processos estão } \\
\text { debaixo de um constante aprimoramento } \\
\text { e fornecem bons resultados. Automação } \\
\text { e ferramentas de softwares são utilizadas } \\
\text { de uma maneira limitada ou } \\
\text { fragmentada. }\end{array}$ & $\begin{array}{l}\text { Há um alto grau de participação dos } \\
\text { membros da administração. A } \\
\text { performance para atingir os resultados } \\
\text { desejados é constantemente monitorada. } \\
\text { Revisões no processo orçamentário são } \\
\text { organizadas ocasionalmente. }\end{array}$ \\
\hline 5 Otimizado & $\begin{array}{l}\text { Os processos foram refinados a um nível } \\
\text { avançado, baseado no resultado de um } \\
\text { contínuo aprimoramento e modelagem } \\
\text { da maturidade como outras organizações. } \\
\text { Toda documentação do processo } \\
\text { orçamentário está automatizada com o } \\
\text { fluxo de trabalho. }\end{array}$ & $\begin{array}{l}\text { O processo orçamentário encontra-se bem } \\
\text { definido, investimento em ferramentas de } \\
\text { softwares que integram todas as áreas } \\
\text { possibilitando relatórios em tempo real. } \\
\text { Responsabilidades bem definidas e em } \\
\text { constante aperfeiçoamento. }\end{array}$ \\
\hline
\end{tabular}

Fonte: Adaptado de IT Governance Institute - www.itgi.org. (2007, p.179).

Com o modelo de Maturidade para o processo Orçamentário será possível avaliar o nível de maturidade da entidade a ser estudada e avaliar quais os passos necessários para aperfeiçoar o processo orçamentário.

\subsection{O ORÇAMENTO NA GESTÃO DA IGREJA CATÓLICA}

Para Padoveze (2005, p.192) "o orçamento é o principal instrumento de gestão para as entidades sem fins lucrativos". Padoveze (2005) enfatiza que estas entidades têm suas receitas baseadas em doações com valores e quantidades quase sempre conhecidas, os custos em sua maioria são fixos e as despesas são peças fundamentais devendo ser elaboradas por atividades ou setores.

Segundo Oliveira e Romão (2011, p.142) “[...] o orçamento é calcular previamente as receitas e despesas da Igreja, levando-se em consideração o tempo em que queremos atingir aquilo que temos projetado e em que aplicaremos os recursos que esperamos receber".

Segundo Delaméa (2001, p.153) “o sistema orçamentário canônico envolve um misto de orçamento público e orçamento privado e, na sua execução, também envolve elementos tipicamente eclesiásticos". 
O orçamento é uma exigência disposta no Código de Direito Canônico. O cân. 493 enfatiza que "[...] compete ao conselho para os assuntos econômicos, preparar todos os anos, segundo as indicações do Bispo diocesano, o orçamento das receitas e despesas, que se preveem para a administração de toda a Diocese no ano seguinte e, no fim do ano, aprovar as contas das receitas e despesas". Conforme o CDC toda Diocese deve constituir um Conselho para assuntos econômicos composto do Bispo que é o presidente, três fiéis peritos em assuntos econômicos e em direito civil, nomeados pelo Bispo (Cân.492).

Ainda, de acordo com o Cân. 494 o Bispo deve nomear um ecônomo (que normalmente é um presbítero) conhecedor de assuntos econômicos e este ecônomo deverá, segundo normas estabelecidas pelo conselho para assuntos econômicos, administrar os bens da Diocese, sob a autoridade do Bispo, e com as receitas da Diocese satisfazer as despesas autorizadas pelo Bispo ou por outros pelo mesmo legitimamente autorizado. E, no fim de cada ano o ecônomo deverá apresentar ao conselho para os assuntos econômicos as contas das receitas e despesas. Segundo Delaméa (2001, p.154) "trata-se do orçamento das entradas e saídas de numerários que, normalmente, serve de base para a administração ordinária das distintas pessoas jurídicas canônicas".

Também, o Cân. $1284 \S 3$ coloca que "muito se recomenda que todos os anos os administradores façam orçamentos das receitas e despesas; deixa-se ao direito particular prescrevê-los e determinar mais concretamente o modo como devem ser apresentados". Esta recomendação conforme esclarece Delaméa (2001, p.153) "trata-se de uma "recomendação" que carrega uma obrigatoriedade tipicamente eclesiástica".

No que se refere a atos que possam comprometer o orçamento ou a situação econômica da diocese, o Cân. 1277 recomenda que o Bispo deve consultar o conselho econômico para praticar atos de administração extraordinária, ou seja, aquisições, investimentos, etc. que ultrapassam os limites pré-estabelecidos pela Diocese.

Os Cân. 638 §1. e Cân. 1292 também tratam destas exigências de prévia autorização.

Segundo Delaméa (2001) o orçamento quantifica as ações e a sua execução envolve elementos da administração, além de exigir uma flexibilidade e o acompanhamento especializado da contabilidade. Esse controle quando se fala em orçamento canônico torna-se extremamente importante, principalmente pelo princípio da flexibilidade orçamentaria na administração eclesiástica e, por sua vez, por se basear no princípio da transparência administrativa.

Para Slomski et al. (2012, p.39):

Os benefícios da apresentação de informações orçamentárias pelas entidades de interesse público e social (terceiro setor) compreendem o cumprimento das obrigações de prestação de contas dos executivos sobre a gestão e uso dos recursos junto aos doadores, conselhos curadores, mantenedores, órgãos de fiscalização e sociedade.

“Os orçamentos canônicos são peças técnicas de grande importância para o cotidiano da contabilidade e de grande utilidade prática para a transparência administrativa tão exigida na organização católica”. (DELAMEA, 2001, p.166). 


\section{MÉTODOS}

O estudo descritivo tem uma preocupação com o plano amostral ou universo onde o levantamento dos dados irá recorrer, portanto necessita de técnicas padronizadas de coleta, como o questionário ou a observação sistemática, ou seja, técnicas estatísticas ou/e qualitativas.

O universo desta pesquisa é constituído por 212 Dioceses e 44 Arquidioceses da Igreja Católica Apostólica Romana instaladas no Brasil. Para abordagem e coleta dos dados, esta pesquisa utilizou o método de levantamento de dados survey e para análise e interpretação dos dados, estatística indutiva.

O método de coletas de dados survey utilizado foi o de questionários eletrônicos auto administrados, ou seja, uma ferramenta da web que permite aos usuários criar questionários, enviar, coletar e gerenciar dados. Assim a ferramenta utilizada foi o Survey Monkey (https://pt.surveymonkey.com), que permitiu o envio dos questionários através dos endereços de e-mail obtidos e link da web para compartilhamento por página de contato disponibilizado no site dos respondentes.

A elaboração do questionário baseou-se na revisão da literatura apresentada neste trabalho. O questionário contém 25 questões de múltipla escolha que têm o objetivo de responder à questão problema desta pesquisa: “O orçamento é utilizado como instrumento de controle interno para gestão das Dioceses e Arquidioceses presentes no Brasil?"”.

Importante destacar também, conforme Quadro 2 abaixo, a associação das questões que determinam cada grau de maturidade do processo orçamentário. As questões de 1 a 8 não foram relacionadas, pois não se enquadram na associação com o grau de maturidade.

Quadro 2 - Relação das questões que determinam o grau de maturidade do processo orçamentário

\begin{tabular}{|c|c|}
\hline Questões & Grau de Maturidade a ser verificado \\
\hline 1) Qual a sua função ou responsabilidade na Diocese? & $\begin{array}{l}\text { Questão não se enquadra na associação com o } \\
\text { grau de maturidade. }\end{array}$ \\
\hline 2) Qual o seu grau de formação? & $\begin{array}{l}\text { Questão não se enquadra na associação com o } \\
\text { grau de maturidade. }\end{array}$ \\
\hline $\begin{array}{l}\text { 3) Caso o respondente tenha colocado Superior Completo } \\
\text { na questão } 2 \text { qual a sua área de formação? }\end{array}$ & $\begin{array}{l}\text { Questão não se enquadra na associação com o } \\
\text { grau de maturidade. }\end{array}$ \\
\hline $\begin{array}{l}\text { 4) Há quanto tempo ocupa esta função ou } \\
\text { responsabilidade? }\end{array}$ & $\begin{array}{l}\text { Questão não se enquadra na associação com o } \\
\text { grau de maturidade. }\end{array}$ \\
\hline $\begin{array}{l}\text { 5) Com que frequência estas ferramentas de controle } \\
\text { interno são utilizadas para a gestão da Diocese? Em uma } \\
\text { escalda de } 1 \text { a } 5 \text { onde } 1 \text { não se utiliza e } 5 \text { frequentemente } \\
\text { utilizada. (controle de caixa, controle de movimentação } \\
\text { bancária, controle de contas a receber, controle de contas } \\
\text { a pagar e orçamento.). }\end{array}$ & $\begin{array}{l}\text { Questão não se enquadra na associação com o } \\
\text { grau de maturidade. }\end{array}$ \\
\hline $\begin{array}{l}\text { 6) Quais as ferramentas utilizadas para a elaboração } \\
\text { destes controles? (Manual, Excel, Word ou Software). }\end{array}$ & $\begin{array}{l}\text { Questão não se enquadra na associação com o } \\
\text { grau de maturidade. }\end{array}$ \\
\hline $\begin{array}{l}\text { 7) A Diocese possui um software que integre todos os } \\
\text { departamentos a contabilidade? }\end{array}$ & $\begin{array}{l}\text { Questão não se enquadra na associação com o } \\
\text { grau de maturidade. }\end{array}$ \\
\hline
\end{tabular}


8) Qual o seu grau de envolvimento na confecção do Orçamento?

9) Como você avalia a importância do orçamento para a gestão da Diocese? Em uma escala de 1 a 5 onde 1 sem importância e 5 extremamente importante.

10) Caso não houvesse uma exigência no Código de Direito Canônico para elaboração do Orçamento a Diocese utilizaria desta ferramenta para administrar?

11) Qual o ciclo orçamentário de sua Diocese?

12) Após aprovação do Orçamento o mesmo é divulgado para: a- não é divulgado; b- apenas para os responsáveis pelo controle do orçado $\mathrm{x}$ realizado; c- a todos os departamentos da Diocese; d- ao conselho econômico da Diocese; e- a todos da Diocese.

13) A área de controladoria / contabilidade participa da elaboração do orçamento?

14) Existe um plano e /ou modelo padronizado para elaboração do orçamento?

15) Todo o processo orçamentário é documentado?

16) Todos os funcionários são estimulados a acompanhar o orçamento?

17) Como você avalia o grau de comprometimento dos funcionários com todo o processo orçamentário? Onde 1 sem qualquer comprometimento e 5 totalmente comprometido

18) Há uma equipe responsável pela elaboração e acompanhamento do processo orçamentário?
Questão não se enquadra na associação com o grau de maturidade.

0 Inexistente - Não existe o reconhecimento da necessidade de um processo orçamentário; ou

1 Inicial / Ad hoc - A organização começa a reconhecer que um processo orçamentário é necessário.

1 Inicial / Ad hoc - A organização começa a reconhecer que um processo orçamentário é necessário.

2 Repetível, porém Intuitivo - A sua operação é dependente do conhecimento e da motivação das pessoas; ou

3 Processo Definido - Os procedimentos não são sofisticados, mas existe a formalização das práticas existentes.

2 Repetível, porém Intuitivo - Neste estágio os funcionários podem não estar conscientes de suas responsabilidades; ou

3 Processo Definido - A execução do processo orçamentário passa a ser realizada por equipes ou áreas.

2 Repetível, porém Intuitivo - A sua operação é dependente do conhecimento e da motivação das pessoas; ou

3 Processo Definido - A execução do processo orçamentário passa a ser realizada por equipes ou áreas.

1 Inicial / Ad hoc - não existe processo padronizado; ou

3 Processo Definido - Os procedimentos não são sofisticados, mas existe a formalização das práticas existentes.

2 Repetível, porém Intuitivo - Orçamentos estão em execução, mas não são documentados; ou 3 Processo Definido - O Processo orçamentário está documentado.

2 Repetível, porém Intuitivo - Neste estágio os funcionários podem não estar conscientes de suas responsabilidades.

2 Repetível, porém Intuitivo - Neste estágio os funcionários podem não estar conscientes de suas responsabilidades; ou

3 Processo Definido - A execução do processo orçamentário passa a ser realizada por equipes ou áreas.

3 Processo Definido - A execução do processo orçamentário passa a ser realizada por equipes ou áreas. 
19) Há reuniões periódicas para análise das variações entre o orçado x realizado?

20) Como você avalia o grau de comprometimento e empenho dos gestores com todo o processo orçamentário? Onde 1 sem qualquer comprometimento e 5 totalmente comprometido

21) Durante o processo orçamentário são adotadas algumas ações para uma melhor condução do processo?

22) Há uma preocupação dos gestores em aprimorar as técnicas a fim de obter melhores resultados? Sendo 1 quando não há preocupação e 5 extremamente preocupado.

23) Como você avalia o investimento em ferramentas como softwares que permitem relatórios em tempo real? Em uma escala de 1 a 5 onde 1 sem importância e 5 extremamente importante.

24) A sua Diocese investe em ferramentas de softwares específicos para o processo orçamentário?

25) O modelo de Maturidade genérico adaptado ao orçamento compreende uma ferramenta que ajuda a avaliar a situação atual da Instituição com relação ao processo Orçamentário. Este modelo possui uma escala de maturidade de 0 a 5 onde 0 quer dizer que inexiste um processo orçamentário e 5 que há um processo avançado com aprimoramento contínuo, ou seja, um processo orçamentário otimizado. De acordo com sua opinião, em que nível de maturidade classificaria o processo orçamentário de sua Diocese?
1 Inicial / Ad hoc - O enfoque geral de gerenciamento é desorganizado; ou

2 Repetível, porém Intuitivo - Uma reunião com enfoque informal é realizada para definir algumas questões; ou

4 - Gerenciado e Mensurável - A performance para atingir os resultados desejados é constantemente monitorada.

1 Inicial / Ad hoc - O enfoque geral de gerenciamento é desorganizado; ou

4 Gerenciado e Mensurável - Há um alto grau de participação dos membros da administração.

4 Gerenciado e Mensurável - Revisões no processo orçamentário são organizadas ocasionalmente; ou

5 Otimizado - Os processos foram refinados a um nível avançado, baseado no resultado de um contínuo aprimoramento e modelagem da maturidade como outras organizações.

4 Gerenciado e Mensurável - Gerencia, monitora, avalia e adota ações para a melhor condução do processo orçamentário; ou

5 Otimizado - Os processos foram refinados a um nível avançado, baseado no resultado de um contínuo aprimoramento e modelagem da maturidade como outras organizações

4 Gerenciado e Mensurável - Automação e ferramentas de softwares são utilizadas de uma maneira limitada ou fragmentada; ou

5 Otimizado - O processo orçamentário encontrase bem definido, investimento em ferramentas de softwares que integram todas as áreas possibilitando relatórios em tempo real.

5 Otimizado - O processo orçamentário encontrase bem definido, investimento em ferramentas de softwares que integram todas as áreas possibilitando relatórios em tempo real.

Avaliação de qual nível de maturidade encontrase o processo orçamentário na Diocese, de acordo com a opinião do respondente.

Fonte: Elaborado pelos autores.

Para simplificar os dados e traçar os objetivos desta pesquisa, será utilizada a técnica estatística análise de conglomerados (cluster analysis). Esta técnica será usada para analisar a 
amostra obtida através desta pesquisa, com o objetivo de estimar o comportamento e características da população.

Assim, a análise através de cluster classifica os indivíduos em grupos semelhantes entre si (quando os objetos dentro dos conglomerados estarão muito próximos) e diferentes de outros clusters (quando os conglomerados distintos estarão afastados).

As análises foram desenvolvidas com o software estatístico IBM SPSS Statistics versão 22, utilizando o método Two Step Cluster, que é a ferramenta mais adequada para grandes bases de dados e também, a mais adequada para amostras com uma ou mais variáveis.

\section{RESULTADOS E DISCUSSÃO}

Conforme dito anteriormente, o universo desta pesquisa é constituído por 212 Dioceses e 44 Arquidioceses da Igreja Católica Apostólica Romana existentes no Brasil, deste total de 256, não foi possível contatar 38, restando, portanto, 218. O questionário foi efetivamente enviado a estas 218 Dioceses e Arquidioceses obtendo um retorno de 56 questionários respondidos (26\%). É importante ressaltar quão fechada é esta Instituição, ponto este que dificulta o processo para se obterem informações que dizem respeito à forma de administrar.

\section{Gráfico 1 - Questionários respondidos}

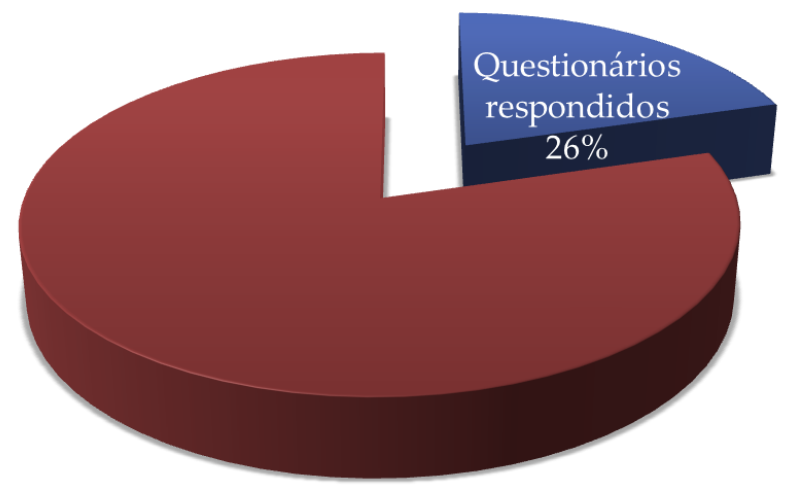

Fonte: Elaborado pelos autores.

Assim, após envio do questionário foram obtidos os seguintes resultados:

- É possível observar que a maioria dos respondentes possuem funções condizentes com a área administrativa e contábil.

- A maioria dos respondentes possui formação superior completa, dos 80,36\% temos as seguintes áreas de formação: Contábeis (26,67\%), Administração (37,38\%), Economia $(6,67 \%)$, Direito $(2,22 \%)$, Outros $(26,67 \%)$. A formação dos respondentes evidencia o grau de conhecimento que estes possuem com relação ao tema desta pesquisa e às questões colocadas. As outras áreas especificadas são: filosofia, teologia e secretariado executivo.

- A maioria tem mais de três anos de experiência na função e é importante ressaltar que estas funções normalmente são de confiança e a estabilidade provavelmente está relacionada a este quesito. 
- O controle de caixa e o controle de movimentação bancária são as ferramentas frequentemente mais utilizadas pelas Dioceses, possivelmente, pelo fato de as Igrejas trabalharem com montantes consideráveis. O orçamento aparece maior nas escalas de 3 a 5, sendo a escala 4 com maior frequência. Este resultado evidencia que o orçamento é utilizado com certa frequência para gestão da Diocese.

- É possível verificar que o software é a ferramenta mais utilizada em todos os controles, exceto para o orçamento que tem como maior ferramenta para sua elaboração o Excel. Sistemas contábeis e de controle interno visam maior precisão para a tomada de decisão, pois asseguram relatórios fidedignos, obviamente todo o processo necessita de mão de obra especializada. $26,67 \%$ dos respondentes possuem área de formação divergente das áreas relacionadas a assuntos econômicos, isso, potencializa o fato de não se utilizar softwares para elaboração do orçamento.

- Apesar de a maioria (51,79\%) dizer possuir um software que integre todos os departamentos a contabilidade é quase proporcional ao número dos que declaram não ter um software que integre $(48,21 \%)$. Sistemas integrados são fundamentais para a criação de controles mais precisos.

- É importante o fato de mais de $90 \%$ dos respondentes estarem totalmente ou parcialmente envolvidos na elaboração do orçamento. Isto demonstra o possível conhecimento que os respondentes possuem com relação ao assunto abordado nas questões e a importância do mesmo.

- O orçamento é reconhecido pela maioria dos respondentes como uma importante ferramenta para gestão da Diocese

- A grande maioria afirma que utilizaria o orçamento como ferramenta para administrar caso não houvesse uma exigência do Código de Direito Canônico (CDC).

- Ciclo orçamentário da maioria dos respondentes é anual. Dos que especificaram outros a resposta foi que não existe ciclo orçamentário.

- A maioria dos respondentes, 37,50\% declara divulgar o orçamento aprovado ao conselho econômico da Diocese. Em seguida, 32,14\% afirmam divulgar apenas aos responsáveis pelo controle do orçado x realizado.

- $73,21 \%$ afirmam que as áreas de controladoria e contabilidade participam da elaboração do orçamento.

- É importante haver ao menos uma estrutura básica e padronizada, $66,07 \%$ dos respondentes declara ter um plano e /ou modelo padronizado para elaboração do orçamento.

- Através desta pesquisa, $46,43 \%$ relatam que não há documentação de todo o processo orçamentário, em contra partida, $42,86 \%$ afirmaram que todo o processo orçamentário é documentado.

- A maioria dos respondentes, $64,29 \%$ colocam que os funcionários não são estimulados a acompanhar o orçamento, apenas 32,14\% dizem que os funcionários são estimulados a acompanhar o orçamento.

- A maioria dos respondentes, 37,50\%, avalia grau 2 em um escala de 1 a 5 para comprometimento dos funcionários com todo o processo orçamentário.

- A maioria dos respondentes, 80,36\% afirmam que há uma equipe responsável pela elaboração e acompanhamento do processo orçamentário.

- A maioria dos respondentes, 53,57\%, afirmam que há reuniões trimestrais para análise das variações entre o orçado $\mathrm{x}$ realizado. Para os que colocaram outro foi especificado reuniões anuais. 
- A maioria dos respondentes, 62,50\% avaliam o grau 3, em uma escala de 1 a 5, como o nível de comprometimento e empenho dos gestores com todo o processo orçamentário.

- Há uma necessidade do retorno e ajustes das peças orçamentárias e $82,14 \%$ dos respondentes confirmam que durante o processo orçamentário são adotadas algumas ações para uma melhor condução do processo.

- Para $66,07 \%$ dos respondentes os gestores se enquadram no grau 3, ou seja, se preocupam, mas possivelmente não se organizam, para aprimorar as técnicas orçamentárias a fim de obter melhores resultados.

- Para $60,71 \%$ dos respondentes é extremamente importante o investimento em ferramentas como softwares que permitem relatórios em tempo real. Nenhum dos respondentes avaliou este tipo de investimento como algo sem importância.

- Apenas 28,57\% dos respondentes dizem que suas Dioceses investem em softwares específicos para o processo orçamentário.

- Sob a percepção da maioria dos respondentes, $41,07 \%$ classifica o grau de maturidade do processo orçamentário de sua Diocese no nível:

2 Repetível, porém Intuitivo - estágio: orçamentos estão em execução, mas não são documentados. A sua operação é dependente do conhecimento e da motivação das pessoas. Neste estágio os funcionários podem não estar conscientes de suas responsabilidades. - Estabelecimento de processos: Avaliações da necessidade do orçamento ocorrem quando necessário. Uma reunião com enfoque informal é realizada para definir algumas questões.

Ainda, para 32,14\% dos respondentes o grau de maturidade se encontra no nível:

3 Processo Definido - estágio: o processo orçamentário está documentado. É mandatório que esses processos sejam seguidos; no entanto, possivelmente alguns problemas não serão detectados. Os procedimentos não são sofisticados, mas existe a formalização das práticas existentes. - Estabelecimento de processos: a execução do processo orçamentário passa a ser realizada por equipes ou áreas. As estruturas organizacionais já estão constituídas.

Avaliando as questões, pode-se concluir que a maioria das Dioceses e Arquidioceses encontram-se no nível 3 do processo orçamentário.

\section{Quadro 3 - Questões e o nível de maturidade}

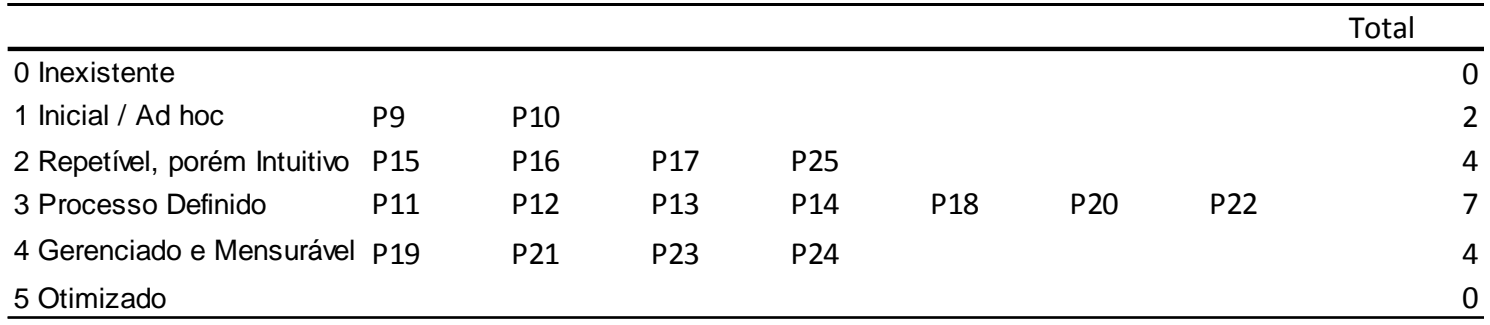

Fonte: Elaborado pelos autores.

\section{Análise através de Clusters}

As variáveis utilizadas foram determinadas de acordo com a importância para o estudo. No intuito de caracterizar da maneira mais ampla possível sua amostra e distinguir dentro dela diferentes grupos, foram utilizadas principalmente as variáveis de avaliação, levando em conta todos os pilares envolvidos para o desenvolvimento deste trabalho e não se limitando a um único aspecto envolvido. 
Foram obtidos dois clusters, sendo que cada grupo possui uma série de características que os diferenciam entre si. Portanto, no presente estudo foi possível classificar todos os casos em dois grupos homogêneos, nos quais temos 50\% (28 casos) classificados no grupo 1 e os outros $50 \%$ ( 28 casos) no grupo 2 .

Os dois grupos resultantes da análise foram criados a partir de sete variáveis, com o intuito de levantar o perfil das Dioceses e Arquidioceses e responder a questão se o orçamento é utilizado como instrumento de controle interno para gestão destas instituições.

\section{Gráfico 2 - Média dos Clusters}

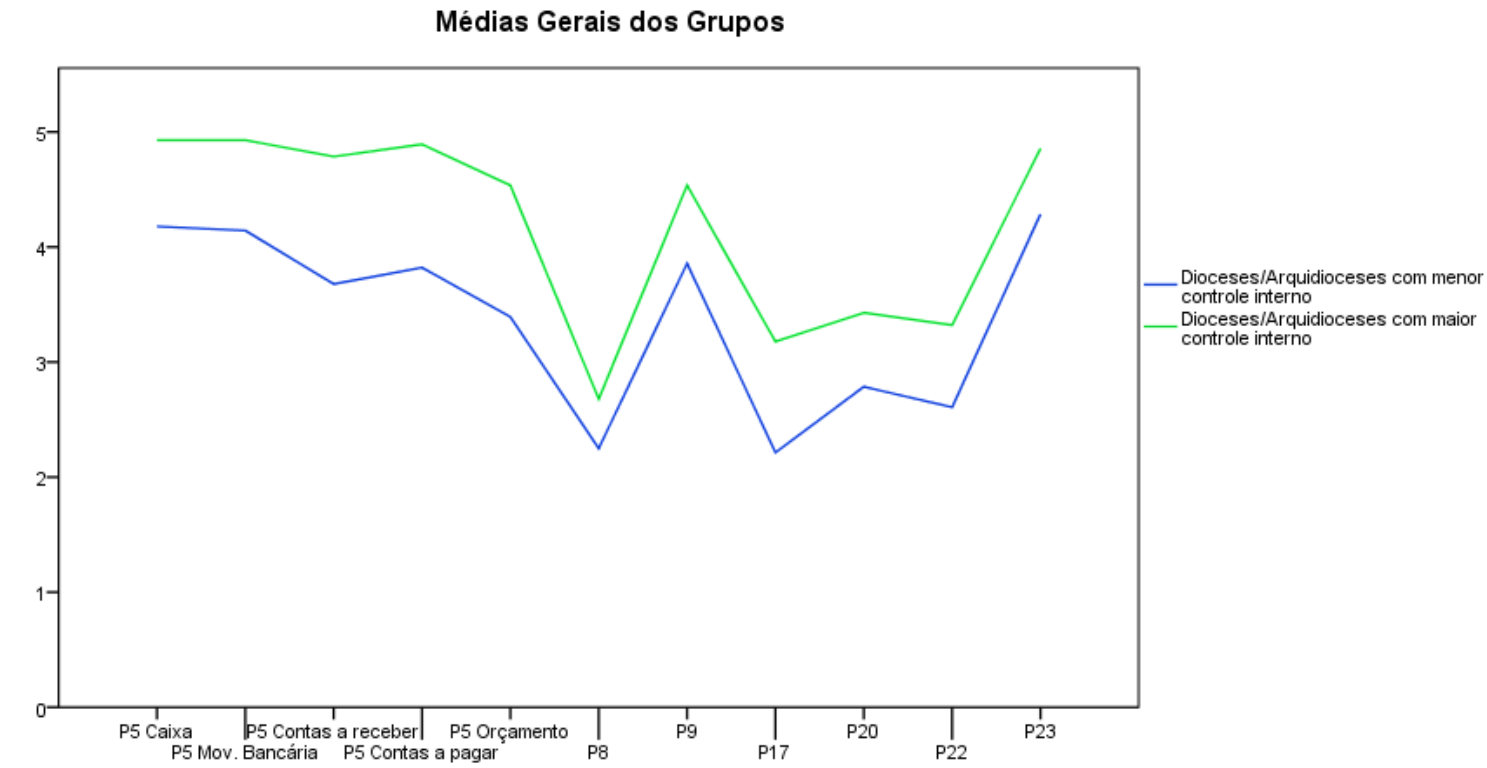

Fonte: Elaborado pelos autores.

O Grupo 1 é denominado "Dioceses/Arquidioceses com menor controle interno" e possui menores médias para todas as questões analisadas. O Grupo 2 denominado "Dioceses/Arquidioceses com maior controle interno" possui médias maiores em todas as questões analisadas.

O grupo denominado Dioceses/Arquidioceses com menor controle interno utiliza com menor frequência, em comparação com as Dioceses/Arquidioceses com maior controle interno, estas ferramentas para controle interno: controle de caixa, controle de movimentação bancária, controle de contas a receber, controle de contas a pagar e orçamento. Além disso, o grupo das Dioceses/Arquidioceses com menor controle interno avalia a importância do orçamento para a gestão da Diocese em uma escala de 1 a 5 uma média de 3,86 enquanto que as Dioceses/Arquidioceses com maior controle interno avaliam dentro de uma média de 4,54.

As Dioceses/Arquidioceses com menor controle interno, 53,6\% se classificam no nível de maturidade para o processo orçamentário 2-Repetível; e das Dioceses/Arquidioceses com maior controle interno 42,9\% se classificam no nível de maturidade para o processo orçamentário 3 - Processo definido, ainda, é importante ressaltar que $14,3 \%$ das 
Dioceses/Arquidioceses com maior controle interno se definem em um nível 5 - otimizado do processo orçamentário.

\section{CONSIDERAÇÕES FINAIS}

Esta pesquisa abordou o tema sobre o orçamento como instrumento de controle interno para gestão das Instituições Eclesiásticas, especificamente nas Dioceses e Arquidioceses presentes no Brasil, com o intuito de corroborar com os controles internos destas Instituições Eclesiásticas e ampliar a discussão a cerca de pesquisas sobre gestão e Contabilidade Eclesiástica.

Após análise e interpretação das informações obtidas, podemos responder a questão problema deste estudo: "O orçamento é utilizado como instrumento de controle interno para gestão das Dioceses e Arquidioceses presentes no Brasil?".

Sim, o orçamento é utilizado como instrumento de controle interno na gestão das Dioceses e Arquidioceses presentes no Brasil, porém, ressalta-se que muitas ainda não utilizam deste instrumento em sua totalidade, ou seja, confeccionam as peças orçamentárias, mas não compreendem a importância de um acompanhamento contínuo dos resultados.

Com a análise obtida através dos clusters foi possível observar características entre os grupos com menor e maior controle interno, evidenciando-se, portanto, que as Dioceses e Arquidioceses que possuem maior controle interno, têm as seguintes características: a) utilizase em sua maioria de softwares para elaboração do orçamento; b) todos elaborariam o orçamento independente do Código de Direito Canônico (CDC); c) participação das áreas de controladoria/contabilidade na elaboração do orçamento; d) possui um modelo padronizado para confecção do orçamento; e) possui uma equipe constituída para acompanhar o processo orçamentário; f) há reuniões em sua maioria trimestrais para verificar as variações entre o orçado $\mathrm{x}$ realizado.

Este resultado demonstra que estabelecer um processo orçamentário uniforme que atenda a todas as Dioceses e Arquidioceses, estimular a utilização de software padronizado que integre todos os departamentos e constituir uma equipe capacitada que acompanhe e verifique as variações do orçado $\mathrm{x}$ realizado em reuniões periódicas é extremamente importante para a utilização do orçamento como um instrumento eficaz de controle interno.

A análise obtida através dos clusters revela que as Dioceses/Arquidioceses com menor controle interno se classificam e realmente se apresentam no nível de maturidade para o processo orçamentário 2-Repetível; e das Dioceses/Arquidioceses com maior controle interno se classificam e através das análises se comprova o nível de maturidade para o processo orçamentário 3 - Processo definido.

Esta pesquisa focou seu estudo nas Instituições Eclesiásticas pertencentes ao terceiro setor, uma vez que, há poucos estudos específicos para a gestão destas instituições. No entanto, a pesquisa sobre orçamento pode contribuir com outras entidades do chamado terceiro setor, que, da mesma forma que as Instituições Eclesiásticas, também trabalham com recursos provenientes de doações, recursos estes na maioria das vezes escassos.

\section{REFERÊNCIAS}


BABBIE, Earl. Métodos de Pesquisas de Survey. Belo Horizonte: Editora UFMG, 2005.

Lei $\mathrm{n}^{\mathrm{o}} 13.019$ de 31 de julho de 2014. Estabelece o regime jurídico das parcerias voluntárias, envolvendo ou não transferências de recursos financeiros, entre a administração pública e as organizações da sociedade civil, em regime de mútua cooperação, para a consecução de finalidades de interesse público; define diretrizes para a política de fomento e de colaboração com organizações da sociedade civil; institui o termo de colaboração e o termo de fomento; e altera as Leis nos 8.429, de 2 de junho de 1992, e 9.790, de 23 de março de 1999. Disponível em: http://www.planalto.gov.br/ccivil_03/_Ato20112014/2014/Lei/L13019.htm. Acesso em: 22 de ago.2014.

CNBB - CÓDIGO DE DIREITO CANÔNICO. Tradução oficial da CNBB. São Paulo: Loyola, 2008.

CNBB - Diretório da Liturgia e da Organização da Igreja no Brasil. Ano A - São Mateus. Brasília: Edições CNBB, 2013.

CONSELHO FEDERAL DE CONTABILIDADE - CFC - Normas brasileiras de contabilidade - NBC. NBC TSP 1 - Apresentação das Demonstrações Contábeis. Disponível em: $\quad<\quad h t t p: / / \quad$ portalcfc.org.br/wordpress/wpcontent/uploads/2012/12/NBC_TSP_1_audiencia.pdf.> Acesso em: 30.nov.2013.

CONSELHO FEDERAL DE CONTABILIDADE - CFC - Normas brasileiras de contabilidade - NBC. NBC TSP 24 - Apresentação da Informação Orçamentária nas Demonstrações Contábeis. Disponível em: <http://www.cfc.org.br/uparq/NBC_TSP _24_audiencia.pdf.> Acesso em: 30.nov.2013.

DELAMÉA, Elenita. Contabilidade eclesiástica: algumas questões operacionais. São Paulo: Loyola, 2001.

DRUCKER, Peter F. Administração de Organizações Sem Fins Lucrativos: Princípios e Práticas. São Paulo: Pioneira, 2002.

FALCÃO, D. Manuel Franco. Enciclopédia Católica Popular. Paulinas, 2004. Disponível em: < http://www.ecclesia.pt/catolicopedia/>. Acesso em: 02.ago.2014.

FERREIRA, Aurélio Buarque de Holanda. Minidicionário da Língua Portuguesa. 3 ed. rev. e ampl. Rio de Janeiro: Nova Fronteira, 1993.

FREITAS, Henrique et al. O Método de pesquisa survey. Revista de Administração, São Paulo v.35, n.3, p.105-112, julho/setembro 2000. Disponível em: www.rausp.usp.br/download.asp?file=3503105.pdf. Acesso em 22.ago.2014

GARCIA, Alexandre Sanches. Introdução à Controladoria: Instrumentos básicos de controle de gestão das empresas. São Paulo: Atlas, 2010.

GIL, Antonio Carlos. Como elaborar Projetos de Pesquisa. 5.ed.São Paulo: Atlas, 2010.

GONCALVES, José Ernesto Lima. Processo, que processo? . RAE - Revista de Administração de Empresas: Out./Dez. 2000. São Paulo, v. 40, n. 4, p.8-19. 
HORNGREN, Charles T.; SUNDEM, Gary L.; STRATTON, William O. Contabilidade Gerencial. 12. ed. São Paulo: Prentice Hall, 2004.

HUDSON, Mike. Administrando Organizações do Terceiro Setor: O desafio de Administrar sem Receita. São Paulo: Pearson Education do Brasil, 2004.

ITGI - Cobit 4.1, Control Objectives for Information and related Technology, 2007. Disponível em: <http://www.itgi.org>. Acesso em: 23.ago.2014.

LUNKES, Rogério João. Manual de Orçamento. 2.ed.São Paulo: Atlas, 2008.

OLAK, Paulo Arnaldo; NASCIMENTO, Diogo Toledo do. Contabilidade para Entidades Sem Fins Lucrativos (Terceiro Setor). São Paulo: Atlas, 2006.

OLIVEIRA, Antonio Benedito Silva. Controladoria: fundamentos do controle empresarial. São Paulo: Saraiva, 2009.

OLIVEIRA, Aristeu de; ROMÃO, Valdo. Manual do terceiro setor e Instituições Religiosas: Trabalhista, Previdenciária, Contábil e Fiscal. 3. ed. São Paulo: Atlas, 2011.

OLIVEIRA, Luís Martins de; PEREZ JR., José Hernandez; SILVA, Carlos Alberto dos Santos. Controladoria Estratégica. 4.ed. São Paulo: Atlas, 2008.

PADOVEZE, Clovis Luís. Planejamento Orçamentário. São Paulo: Pioneira Thomson Learning, 2005.

PAES, José Eduardo Sabo. Fundações, associações e entidades de interesse social: aspectos jurídicos, administrativos, contábeis, trabalhistas e tributários. 8. ed. Rio de Janeiro: Forense, 2013.

SLOMSKI, Valmor et al. Contabilidade do Terceiro Setor: Uma abordagem operacional aplicável às associações, fundações, partidos políticos e organizações religiosas. São Paulo: Atlas, 2012.

TARIFA, Marcelo Resquetti; ALMEIDA, Lauro Brito de; ESPEJO, Marcia Maria dos Santos Bortolocci. Cultura Organizacional e Práticas Orçamentárias: Um Estudo Empírico nas Maiores Empresas do Sul do Brasil. Disponível em: http://www. congressousp.fipecafi.org/web/artigos92009/386.pdf. Acesso em: 27.set.2014

VATICANO. A Cúria Romana. Disponível em: http://www.vatican.va/roman curia/index_po.htm. Acesso em: 18 mai.2014.

WEST, Robert; ZECH, Charles. Internal Financial Controls in the U.S. Catholic Church. Journal of forensic accounting: JFA; auditing, fraud \& risk.- Philadelphia, Pa: Edwards, ISSN 1524-5586, ZDB-ID 22671432. - Vol. 9.2008, 1, p. 129-155 Disponível em: http://www1.villanova.edu/content/dam/villanova/VSB/publications/ catholicchurchfinances.pdf. Acesso em: 20.mai.2014 